and vena contracta of $0.6 \mathrm{~cm}$ (Figure 1, A). The aortic annulus was measured at $24 \mathrm{~mm}$. Preoperative computed tomography showed an effective aortic valve annulus of $24 \mathrm{~mm}$ and a perimeter of $80 \mathrm{~mm}$, the sinotubular size was $35 \mathrm{~mm}$, and the aortic bulge was described at 36 $\mathrm{mm}$. Because of her high perioperative risk and small, calcified femoral arteries, multidisciplinary team chose transapical aortic valve implantation. Owing to its positioning and anchoring facilities within the aortic root, the Engager valve (Medtronic, Inc, Minneapolis, Minn), with a size of $26 \mathrm{~mm}$ was chosen for implantation. The valve size was dependent on the annulus size, which was determined using both transesophageal echocardiography and computed tomography. Transapical access was achieved through left anterior minithoracotomy. After passing the native valve with the device, the arches were released and placed in the coronary sinuses (Figure 1, $B)$. Therefore, valve embolization into the left ventricle was almost impossible. By pulling the device slightly toward the left ventricle, the valve was finally released (Figure 1,C). The initial invasive measurement showed a trace residual aortic insufficiency and a peak gradient of $5 \mathrm{~mm} \mathrm{Hg}$. The mitral valve insufficiency immediately decreased from grade II to III to grade I.

The patient experienced atrioventricular blockage (grade III) and required pacemaker implantation but was discharged on postoperative day 12 .

\section{Reference}

1. Cribier A. Development of transcatheter aortic valve implantation (TAVI): a 20-year odyssey. Arch Cardiovasc Dis. 2012;105:146-52.

\title{
Direct aortic transcatheter aortic valve implantation for pure aortic valve regurgitation after implantation of a left ventricular assist device
}

\author{
René Krause, MD, Dietrich Metz, MD, and Hasan Bushnaq, MD, Halle, Germany
}

The increasing use of continuous-flow left ventricular assist devices (LVADs) for the purpose of destination therapy has led to associated secondary aortic valve insufficiency (AI) as a significant complication. ${ }^{1,2}$ Significant AI can lead to ineffective LVAD output and end-organ malperfusion, with consequent symptoms of congestive heart failure and significantly worse survival. ${ }^{3}$ The management of this condition is challenging.

\section{CLINICAL SUMMARY}

A 65-year-old woman with an LVAD was readmitted to our heart center because of recently increased shortness of breath at rest. The patient's medical history included ischemic cardiomyopathy, chronic obstructive pulmonary disease, pulmonary hypertension, moderate impaired renal function, and type II diabetes mellitus. Because of the

From the Department of Cardiac and Thoracic Surgery, Martin-Luther-University Halle-Wittenberg, Halle, Germany.

Disclosures: Hasan Bushnaq reports consulting fees from Medtronic and HeartWare. All other authors have nothing to disclose with regard to commercial support.

Received for publication Oct 20, 2013; revisions received Nov 23, 2013; accepted for publication Nov 29, 2013; available ahead of print Feb 2, 2014.

Address for reprints: Hasan Bushnaq, MD, Department of Cardiac and Thoracic Surgery, Martin-Luther-University Halle-Wittenberg, D-06097 Halle, Germany (E-mail: hasan.bushnaq@uk-halle.de).

J Thorac Cardiovasc Surg 2014;147:e38-41

$0022-5223 / \$ 36.00$

Copyright (C) 2014 by The American Association for Thoracic Surgery

http://dx.doi.org/10.1016/j.jtcvs.2013.11.039 end-stage ischemic cardiomyopathy with terminal heart failure (New York Heart Association class IV), she had undergone an LVAD implantation (HeartMate II; Thoratec Corporation, Pleasanton, Calif) from the left ventricular apex to the ascending aorta through a sternotomy in December 2009 (Figure 1).

Thereafter the patient recovered to a good general status. During the routine follow-ups in 2012, she reported increasing shortness of breath at daily activities. Echocardiography showed at this time a new finding of AI of grade II. Despite optimal medical therapy and LVAD adjustments, her symptoms remained. The repeated echocardiography after emergency admission showed moderate AI with volume overload of the left side of the heart as a result of a continuous AI during systole and diastole (Figure 2). The cusps and the annulus showed a mild degeneration as well as an altered coapting function. LVAD function was completely accurate. During hospitalization with optimal medical treatment, the patient's condition gradually deteriorated. She was therefore submitted for surgical treatment of the AI.

Because of the patient's poor general status, the multimorbidity and conducted heart surgery, we decided to attempt transcatheter aortic valve implantation (TAVI). The direct aortic access was chosen because of our previous good experiences with this procedure. In this case, it provided some advantages to the femoral access. 


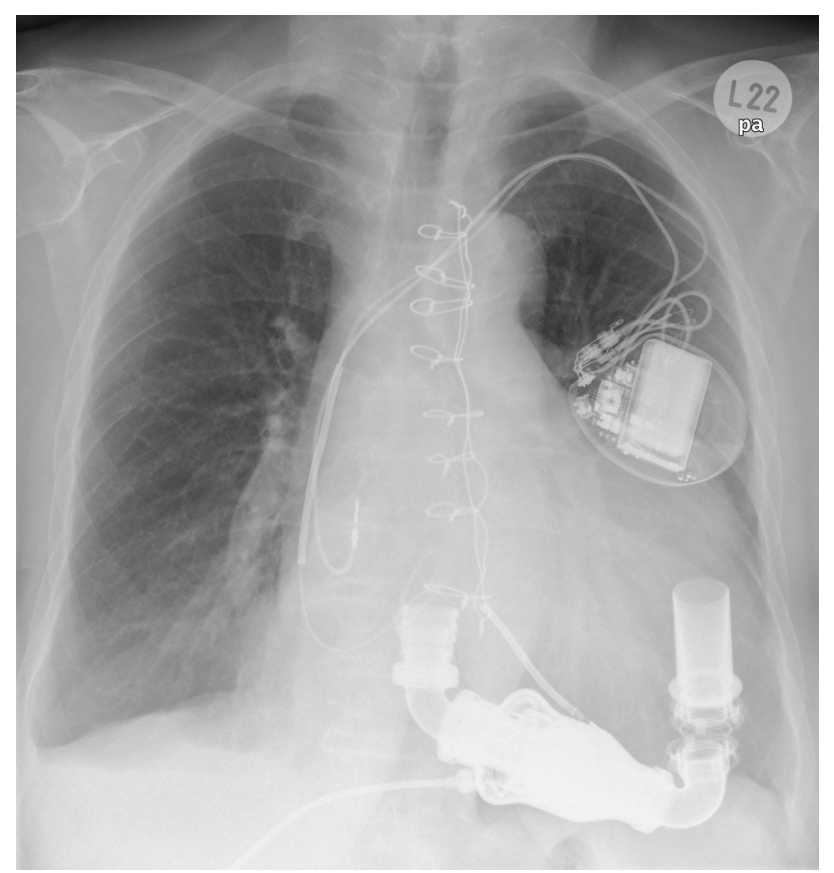

FIGURE 1. Standard posteroanterior chest radiograph shows the left ventricular assist device (HeartMate II) and an implantable cardioverter defibrillator.

Preoperative chest computed tomography and transesophageal echocardiography were performed. Both showed absent valvular calcification and depicted the exact position of the outflow cannula. The perimeter of the aortic annulus was measured by computed tomography at $26 \mathrm{~mm}$ and by transesophageal echocardiography at $27 \mathrm{~mm}$. We therefore used an oversizing of $20 \%$ for choosing prosthesis size.

The procedure was performed by the senior author (H.B.) and our interdisciplinary TAVI team. We performed an upper partial ministernotomy with a J sternal incision (Figure 3). A 31-mm Medtronic CoreValve (Medtronic Inc, Minneapolis, Minn) was slowly deployed under angiographic and echocardiographic guidance. After it was released in an accurate position, the CoreValve migrated toward left ventricular outflow tract, resulting in a moderate periprosthetic AI. We therefore successfully implanted a second $31-\mathrm{mm}$ valve as a valve-in-valve technique (Figure 4). The LVAD parameters were unchanged through the procedure, with stable hemodynamic conditions. The extubation was proceeded in the operating room and the patient was transferred to the regular ward on the first postoperative day.

At follow-up 3, 6, and 12 months later, she was living independently at home in New York Heart Association class II. Echocardiography showed the prosthesis in a stable position without evidence of further AI.

\section{DISCUSSION}

The feasibility of TAVI in patients with implanted LVADs has previously been reported. ${ }^{4,5}$ To the best of our knowledge, however, the direct aortic approach in this condition has never been documented in the literature. Additionally, until now there has been limited experience of the use of TAVI for pure native aortic valve regurgitation without aortic stenosis. Absent aortic valve

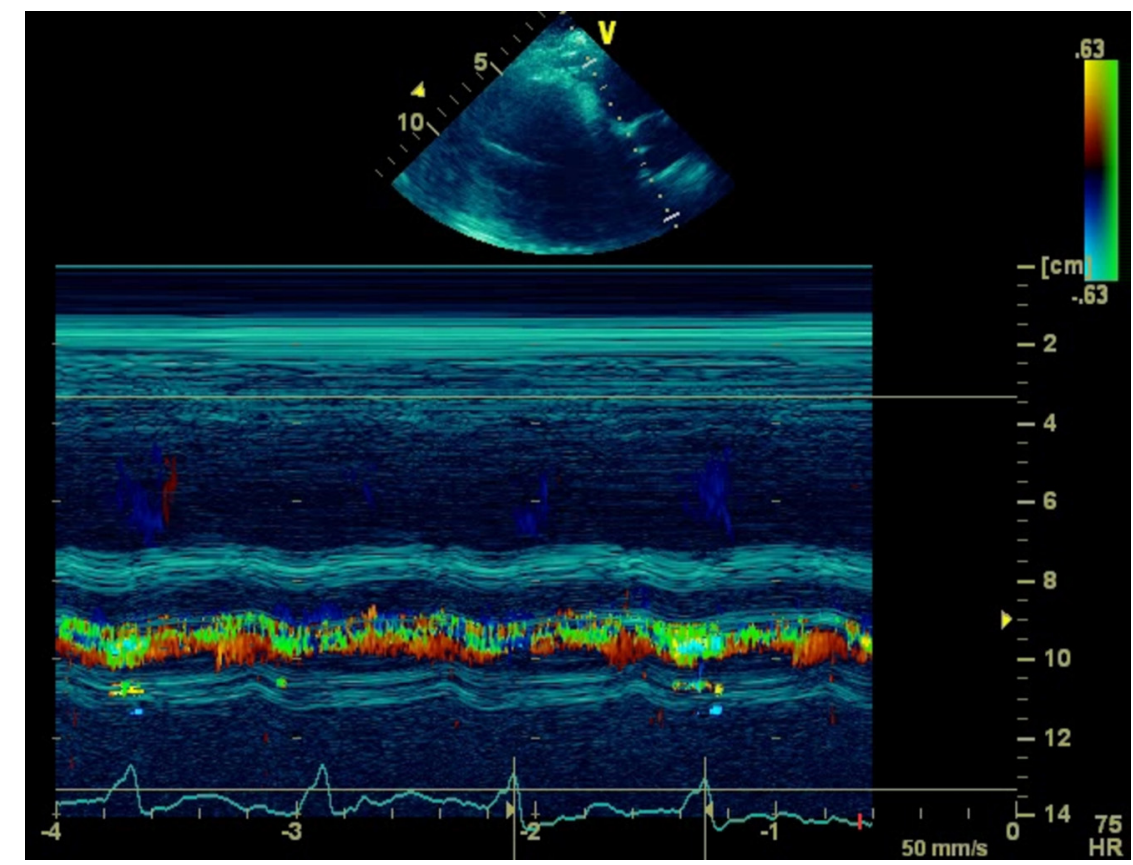

FIGURE 2. Color Doppler M-mode echocardiography of the aortic valve insufficiency in the parasternal long-axis view shows continuous blood flow to the left ventricle. 


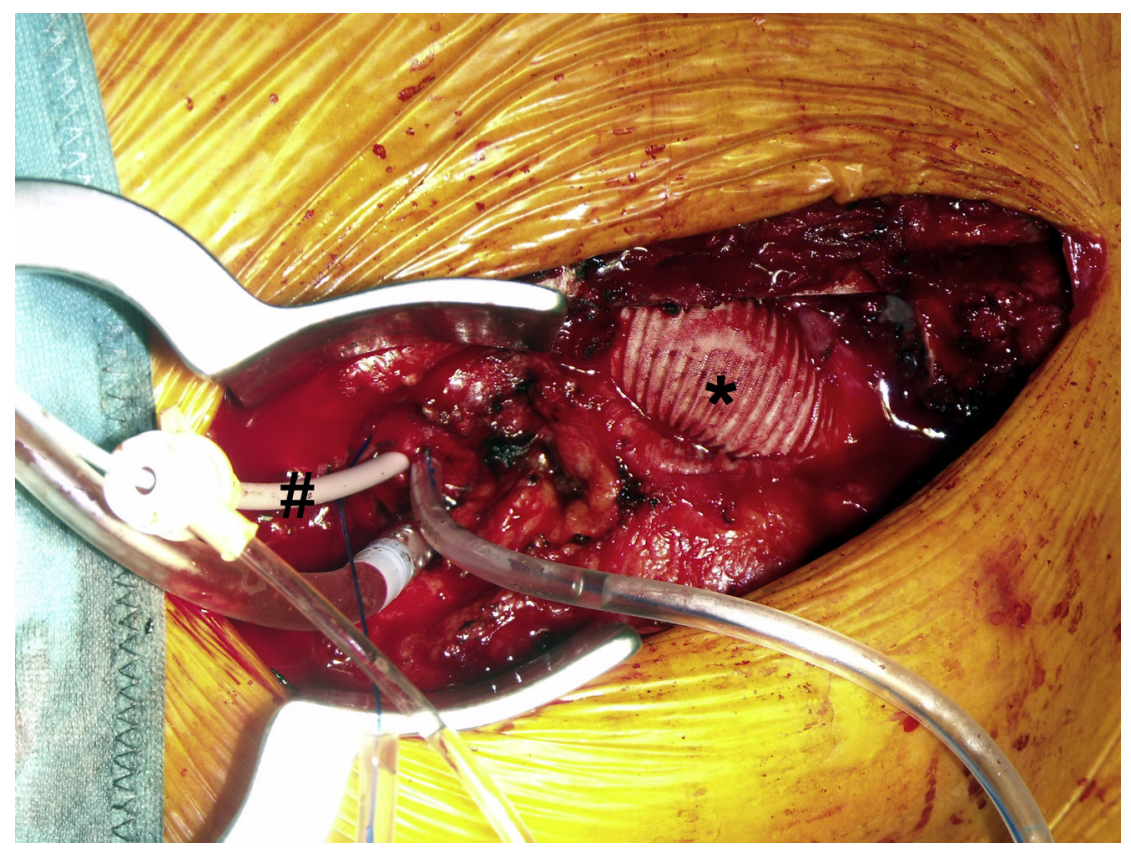

FIGURE 3. Primary access was obtained through a ministernotomy. Asterisk indicates left ventricular assist device outflow cannula; hash mark indicates $5 \mathrm{~F}$ sheath in the distal ascending aorta.

calcification may hamper the anchoring of the prosthesis, resulting in malpositioning. A recently published registry analysis demonstrates that there is an increased need for a second valve in that condition. ${ }^{6}$ In this case, the patient had an elongated ascending aorta with widened annulus of $27 \mathrm{~mm}$ and absent calcification. In our experience, direct aortic access was the favorable approach to that condition.

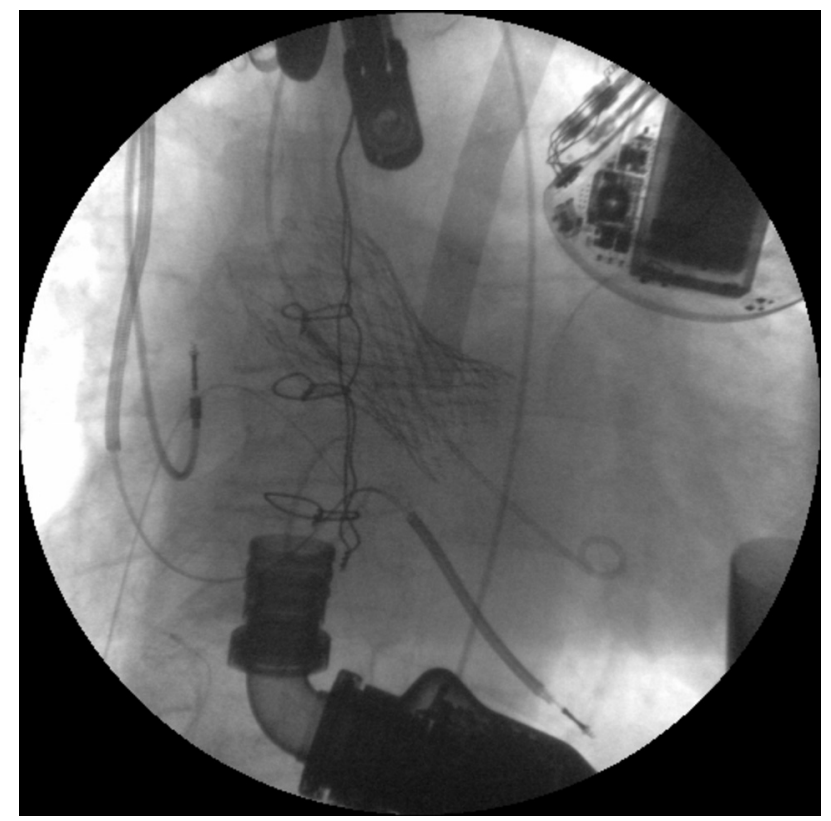

FIGURE 4. Posteroanterior radiograph obtained by using a standard C-bow shows the final result with 2 CoreValves, both $31 \mathrm{~mm}$, implanted as a valve-in-valve technique.
Because of the elongation of the ascending aorta, the direct aortic access ensured an optimal angle for valve deployment as well as excellent control of the catheter. Furthermore, it provided optimal management of possible therapy conversion and complications as well as full hemodynamic support by the LVAD. After deployment of the 31-mm CoreValve in an accurate position, it migrated toward the left ventricular outflow tract with concomitant moderate AI and the need for a second valve. We suppose that in addition to the anatomy this may be addressed to the blood flow to the inflow cannula as well as the deficient output of the left ventricle. We would recommend decreasing the LVAD speed during deployment when using a self-expanding device. In addition, anatomic issues might be improved with future valve generations with improved fixation and anatomically oriented designs.

Because there are several approaches to manage pure aortic valve regurgitation in patients with LVADs, one must consider percutaneous transcatheter aortic valve closure. ${ }^{7}$ Further data are needed to evaluate the advantages of these procedures. Direct aortic TAVI remains a safe procedure, however, and can be a reasonable option even in patients with LVADs who are deemed to be in an inoperable condition.

\section{References}

1. Aggarwal A, Raghuvir R, Eryazici P, Macaluso G, Sharma P, Blair C, et al. The development of aortic insufficiency in continuous-flow left ventricular assist device-supported patients. Ann Thorac Surg. 2013;95:493-8.

2. Cowger J, Pagani FD, Haft JW, Romano MA, Aaronson KD, Kolias TJ. The development of aortic insufficiency in left ventricular assist device-supported patients. Circ Heart Fail. 2010;3:668-74. 
3. Toda K, Fujita T, Domae K, Shimahara Y, Kobayashi J, Nakatani T. Late aortic insufficiency related to poor prognosis during left ventricular assist device support. Ann Thorac Surg. 2011;92:929-34.

4. D’Ancona G, Pasic M, Buz S, Drews T, Dreysse S, Hetzer R, et al. TAVI for pure aortic valve insufficiency in a patient with a left ventricular assist device. Ann Thorac Surg. 2012;93:e89-91.

5. Santini F, Forni A, Dandale R, Ribichini F, Rossi A, Franchi G, et al. First successful management of aortic valve insufficiency associated with HeartMate II left ventricular assist device support by transfemoral Core-
Valve implantation: the Columbus's egg? JACC Cardiovasc Interv. 2012;5 $114-5$.

6. Roy DA, Schaefer U, Guetta V, Hildick-Smith D, Möllmann H, Dumonteil N, et al Transcatheter aortic valve implantation for pure severe native aortic valve regurgitation. J Am Coll Cardiol. 2013;61:1577-84

7. Parikh KS, Mehrotra AK, Russo MJ, Lang RM, Anderson A, Jeevanandam V, et al Percutaneous transcatheter aortic valve closure successfully treats left ventricular assist device-associated aortic insufficiency and improves cardiac hemodynamics. JACC Cardiovasc Interv. 2013:6:84-9.

\title{
Potential myocardial regeneration with CorMatrix ECM: A case report
}

\author{
Bobby Yanagawa, MD, PhD, Vivek Rao, MD, PhD, Terrence M. Yau, MD, MSc, and \\ Robert J. Cusimano, MD, Toronto, Ontario, Canada
}

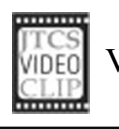

Video clip is available online.

Pericardial and polytetrafluoroethylene patches are currently the most commonly used materials for intraventricular repair but are limited by calcification and retraction. The extracellular matrix (ECM) biomaterial CorMatrix ECM (CorMatrix Cardiovascular, Inc, Roswell, Ga) is an absorbable tissue scaffold synthesized from decellularized porcine small intestinal submucosa that is rich in collagen, glycosaminoglycans, and growth factors. Furthermore, in experimental models of myocardial infarction and ventricular repair, ECM patches have been shown to stimulate infiltration of cells, including cardiomyocytes, as well as ECM production. ${ }^{1,2}$

The epicardial application of CorMatrix ECM has been demonstrated to decrease infarct size and scar formation after myocardial infarction. ${ }^{3}$ We have previously studied the operative safety of the use of CorMatrix ECM for left ventricular aneurysm repair and ventricular septal defect repairs, with no primary repair failures. ${ }^{4}$ Here we report a case of ventricular false aneurysm repair with

\footnotetext{
From the Division of Cardiovascular Surgery, University Health Network, Department of Surgery, University of Toronto, Toronto, Ontario, Canada.

Disclosures: V.R. is a consultant for, is on the Medical Advisory Committee of the Board of Directors of, and receives compensation in the form of stock options from CorMatrix Cardiovascular, Inc, Roswell, Ga. All other authors have nothing to disclose with regard to commercial support.

Received for publication Nov 17, 2013; accepted for publication Dec 4, 2013; available ahead of print Feb 14, 2014.

Address for reprints: Robert J. Cusimano, MD, The Toronto General Hospital, 200 Elizabeth St, 4N-468 Toronto, ON M5G 2C4, Canada (E-mail: robert.cusimano@ uhn.ca).

J Thorac Cardiovasc Surg 2014;147:e41-3

$0022-5223 / \$ 36.00$

Copyright (C) 2014 by The American Association for Thoracic Surgery

http://dx.doi.org/10.1016/j.jtcvs.2013.12.012
}

CorMatrix ECM, which resulted in improvement of ventricular contractile activity at 1-year follow-up.

\section{CLINICAL SUMMARY}

A 75-year-old female patient underwent 3-vessel coronary artery bypass grafting 9 years before the index visit, then 3 years before the index visit had an acute infarction with ventricular rupture. She underwent sutureless repair of a false aneurysm with Bioglue (CryoLife, Inc, Kennesaw, $\mathrm{Ga}$ ) closure of the lateral ventricular wall.

The patient reported chest pain and syncope. Angiography revealed a superficial false aneurysm $(54 \times 24 \mathrm{~mm})$ superimposed on a deeper false aneurysm $(72 \times 49 \mathrm{~mm}$; Figure 1, $A$, and Video 1). Transthoracic echocardiography demonstrated inferior and inferolateral hypokinesis of the left ventricle (left ventricular ejection fraction 20\%-40\%), ventricular dilation (left ventricular endsystolic diameter $39 \mathrm{~mm}$ and left ventricular end-diastolic diameter $53 \mathrm{~mm}$ ), mild mitral regurgitation, and large false aneurysms.

The patient underwent CorMatrix ECM false aneurysm repair with femoral cannulation through a left thoracotomy. The false aneurysm was opened under deep hypothermic circulatory arrest $\left(28^{\circ} \mathrm{C}\right)$. The communication between the superficial and deep false aneurysm was approximately $20 \times 20 \mathrm{~mm}$, and the more recent false aneurysm was filled with thrombus. The neck of the old false aneurysm extending from the base of the papillary muscles to the apex was closed with CorMatrix ECM with running 4-0 monofilament suture. The superficial false aneurysm was then closed. The patient was rewarmed and decannulated.

Immediate postoperative echocardiography demonstrated inferolateral and anterolateral mid-to-apical akinesis of the left ventricle (left ventricular ejection fraction $35 \%-45 \%$, left ventricular end-systolic diameter $35 \mathrm{~mm}$, left ventricular end-diastolic diameter $42 \mathrm{~mm}$; Figure 1, $B$ 